\title{
Anion Size Does Not Compromise Sodium Recognition by Rats After Acute Sodium Depletion
}

\author{
Laura C. Geran and Alan C. Spector \\ University of Florida
}

\begin{abstract}
Amiloride-insensitive sodium taste transduction is severely limited by large anions (i.e., gluconate). We found that in a brief-access taste test, sodium-depleted rats exhibited similar levels of increased licking to several sodium salts regardless of anion but did not increase licking to nonsodium salts compared with water. The enhanced licking of sodium salts was abolished in the presence of amiloride. These results suggest that the amiloride-sensitive taste transduction pathway is not only necessary but that it is also sufficient for sodium identification in rats. Sodium-depleted rats tested with amiloride initiated significantly more trials than nondepleted rats; hence, appetitive behavior was mildly potentiated by depletion, even in the absence of a sodium taste cue. Overall, these findings provide compelling support for the primacy of the amiloride-sensitive taste transduction mechanism and its associated neural pathway in the recognition of the sodium cation.
\end{abstract}

When rats are in a sodium-depleted state, the apparent perception of a "sodium-like" taste quality will promote ingestion of the stimulus (e.g., Falk \& Herman, 1961; Handal, 1965; Nachman, 1962; Richter \& Eckert, 1938). This depletion-induced elevation of intake, termed sodium appetite, is specific for sodium and lithium salts (Nachman, 1962) and has been described in a number of mammals (see Denton, 1982; Schulkin, 1991). Researchers have used this phenomenon for several decades to test hypotheses about salt taste perception, most notably through the use of brief-access taste tests which substantially reduce the contribution of postingestive receptors (e.g., Breslin, Spector, \& Grill, 1993; Falk \& Herman, 1961; Handal, 1965; Nachman, 1962).

The ability of rats to recognize the taste of sodium when in a sodium-depleted state appears to depend on taste receptor cells in the oral cavity that contain passive ion channels selective for sodium and lithium ions (Bernstein \& Hennessy, 1987; McCutcheon, 1991; Roitman \& Bernstein, 1999). The sodium-selective ion channels, or epithelial sodium channels (ENaCs), expressed by these cells can be blocked with the drug amiloride (see Brand, Teeter, \& Silver, 1985; DeSimone \& Ferrell, 1985; Doolin \& Gilbertson, 1993; Heck, Mierson, \& DeSimone, 1984; Schiffman,

Laura C. Geran and Alan C. Spector, Department of Psychology and Center for Smell and Taste, University of Florida.

This research was supported by Grants R01-DC01628 and F31DC05107 from the National Institute on Deafness and Other Communication Disorders. Portions of this work were presented at the annual meeting of the Association for Chemoreception Sciences in Sarasota, Florida, April 2000, and were in partial fulfillment of the requirements for the degree of Doctor of Philosophy (Laura C. Geran) at the University of Florida.

We wish to thank Mircea Garcea and Edmund Rodgers for their assistance with animal care. We would also like to thank Barry Ache, Darragh Devine, Timothy Hackenberg, and Neil Rowland for their comments on an earlier version of this article.

Correspondence concerning this article should be addressed to Alan C. Spector, Department of Psychology, Box 112250, University of Florida, Gainesville, FL 32611-2250. E-mail: spector@ufl.edu
Lockhead, \& Maes, 1983). A second transduction pathway for sodium, the amiloride-insensitive (AI) pathway, is not sodium selective but instead appears to be activated by a variety of cations, including $\mathrm{Na}^{+}, \mathrm{K}^{+}$, and $\mathrm{NH}_{4}^{+}$(Brand et al., 1985; DeSimone \& Ferrell, 1985; Kloub, Heck, \& DeSimone, 1997; Ye, Heck, \& DeSimone, 1994). Instead of ions passing directly through apical $\mathrm{ENaCs}$, activation of this pathway is thought to involve the diffusion of ions across tight junctions and also perhaps through less selective ion channels in the apical membrane (DeSimone \& Ferrell, 1985; DeSimone et al., 2001; Elliot \& Simon, 1990; Simon, 1992; Ye, Heck, \& DeSimone, 1993, 1994). Activation of the AI pathway can be significantly reduced by pairing the cation with an anion of large hydrated radius, like acetate or gluconate, thus reducing the diffusion of ions across tight junctions (Elliot \& Simon, 1990; Rehnberg, Mackinnon, Hettinger, \& Frank, 1993; Simon, 1992; Ye et al., 1993). Although recent data support the existence of an amiloride-insensitive, nonselective cation channel in the apical membrane (DeSimone et al., 2001; Gilbertson \& Zhang, 1998), large anion salts apparently do not significantly stimulate this pathway. Potassium gluconate, for example, is a very poor stimulus (Stewart, Heck, \& DeSimone, 1996; Ye et al., 1994), and amiloride treatment virtually eliminates the chorda tympani nerve $(\mathrm{CT})$ response to sodium acetate $(\mathrm{NaAc})$ and sodium gluconate (NaGlu), especially at low to mid-range concentrations (Elliot \& Simon, 1990; Formaker \& Hill, 1988; Ye et al., 1993).

Previously, it has been shown that the amiloride-sensitive (AS) pathway is both necessary and sufficient for normal $\mathrm{Na}^{+}$detection in the rat, at least to the extent that gluconate is capable of blocking AI transduction (Geran \& Spector, 2000a, 2000b). It is possible, however, that these near-threshold concentrations, although detectable, were not perceived as tasting sodium-like by the animals. For instance, humans often report that low concentrations of $\mathrm{NaCl}$ taste "sweet" rather than "salty" (Bartoshuk, Murphy, \& Cleveland, 1978). Consequently, we tested whether reducing the contribution of the AI pathway (or pathways) with a large anion affected sodium recognition. Other researchers have shown that rats will ingest a variety of sodium salts when depleted of sodium (Fregly, 
1958; Handal, 1965; Krieckhaus \& Wolf, 1968; Morrison \& Young, 1971; Nachman, 1962; Richter \& Eckert, 1938; Schulkin, 1982); however, no one to our knowledge has made a direct comparison among sodium salts using different concentrations in a brief-access test. A brief-access test was used so that preference for several salts could be analyzed simultaneously without potentially confounding postingestive effects. Three sodium salts with different sized anions were used to limit AI transduction (Elliot \& Simon, 1990; Formaker \& Hill, 1988; Kitada, Mitoh, \& Hill, 1998; Ye et al., 1993). Sodium gluconate in particular was chosen on the basis of its ineffectiveness in stimulating AI transduction (Ye, Heck, \& DeSimone, 1991; Ye et al., 1993). This experiment marks the first time to our knowledge that sodium gluconate has been presented to sodium-depleted rats. Two concentrations of each salt were chosen on the basis of mean sodium detectability functions measured previously (Geran \& Spector, 2000a, 2000b). One concentration was well above detection threshold in the presence of amiloride $(0.3 \mathrm{M})$, and the other was below threshold when mixed with amiloride but above threshold in the absence of amiloride $(0.03 \mathrm{M})$. Potassium chloride and $\mathrm{NH}_{4} \mathrm{Cl}$ were included in the stimulus array for the purpose of comparison. If the AS pathway is sufficient as well as necessary for sodium recognition, sodiumdepleted animals should show similar amounts of licking to all sodium salts, regardless of anion. Furthermore, this increase in licking to sodium salts should be abolished with the addition of amiloride.

\section{Method}

\section{Subjects}

A total of 40 naive male Sprague-Dawley rats (Charles River Breeders, Wilmington, MA) were used in this experiment. Subjects were tested in two groups of 20. All rats weighed approximately $250-300 \mathrm{~g}$ at the start of training and were placed on a 12:12-hr light-dark schedule with lights on at 6 a.m. Humidity and temperature were automatically controlled. Rats were individually housed in hanging wire mesh cages and given ad-lib access to laboratory chow (PMI 5001 pellets, PMI Nutrition International, Brentwood, MO), except where noted. Access to distilled water, however, was restricted while in the home cage. Water bottles were removed approximately $24 \mathrm{hr}$ prior to training and replaced after the last training session 5 days later. Rats had access to water only during 30-40-min training sessions on these 5 days. Body weights were closely monitored for excessive dehydration. No rat dropped below $85 \%$ of its individual ad libitum weight during this experiment. All procedures were approved by the University Institutional Animal Care and Use Committee at the University of Florida.

\section{Apparatus}

All training and testing occurred in a modified, automated taste-testing apparatus called a gustometer (Spector, Andrews-Labinski, \& Letterio, 1990). This apparatus was designed to deliver small volumes of fluid stimuli and record the number of licks for each stimulus presented. A narrow slot in one wall of the chamber enabled the rat to access a vertically oriented sample spout. This spout rotated into position in front of the slot at appropriate times throughout the session. Each taste stimulus was kept in a pressurized syringe connected to the sample spout by way of Teflon tubing and a solenoid valve. Each valve was opened for a preset amount of time by the computer such that each lick delivered approximately $5 \mu 1$ of fluid after the drinking shaft was initially loaded with the stimulus (see Spector et al., 1990, for more details on stimulus delivery). A very low current $(<50 \mathrm{nA})$ contact circuit was used to monitor number of licks taken.

\section{Training Procedure}

On the 1st day of training, a drop of water was placed on the tip of the spout and on the inside wall of the chamber before each session to help in training the rat to drink from the spout. During the first 2 days of training, the sample spout remained motionless in front of the access slot so that the rat had continuous access to distilled water for each 30-min session. After all animals had been trained to lick from the spout, they received 3 days of additional spout training in which they received access to distilled water and $0.1 \mathrm{M}$ sucrose in 5-s trials. Sucrose was used to encourage stimulus sampling. The rat was required to lick the dry spout twice in $1 \mathrm{~s}$ to receive a stimulus presentation. When the trial was finished, the spout rotated away from the access slot and over a funnel where it was rinsed with distilled water and dried with pressurized air. This process took about $6 \mathrm{~s}$ to complete. The spout then rotated back in front of the slot. These sessions lasted $40 \mathrm{~min}$.

\section{Sodium Depletion}

After training was complete, rats were assigned to one of four groups. These groups were counterbalanced for body weight, number of trials initiated during the last 3 days of training, and mean number of total licks for these 3 days. Distilled water bottles were placed on the home cages on Friday, after the last training session. On the next Monday morning, the rats were moved from their standard cages to metabolism cages equipped with funnels to collect urine. They were also given a weighed amount of powdered chow at this time instead of pellets. Rats in the two sodiumdepleted groups received Harlan Teklad 90228 sodium-deficient $(0.02 \%$ $\mathrm{NaCl}$ ) chow (Harlan Teklad, Madison, WI). Rats in the two nondepleted groups received the same chow mixed with $1.0 \% \mathrm{NaCl}$. Twenty-four hours prior to testing, each rat in the sodium-depleted groups received the first of two equal volumes of furosemide (total dose $=30 \mathrm{mg} / \mathrm{kg} \mathrm{BW}$, s.c.). The second furosemide injection was given $2 \mathrm{hr}$ later. Rats in the nondepleted groups received injections of isotonic saline (s.c.), using the same injection schedule and volume as rats given furosemide. Subjects had free access to powdered chow (with or without sodium) and distilled water during the sodium depletion phase of the experiment. Urine was collected in 100-mL flasks for $24 \mathrm{hr}$ immediately following the first injection.

\section{Brief-Access Testing}

Testing took place in the gustometers $24 \mathrm{hr}$ after each animal's first furosemide injection. Animals were given brief access to 11 stimuli (e.g., distilled water and 0.03 and $0.3 \mathrm{M}$ concentrations of $\mathrm{NaCl}, \mathrm{KCl}, \mathrm{NH}_{4} \mathrm{Cl}$, sodium acetate [NaAc], and sodium gluconate [NaGlu]) over a 40-min period. Stimuli were presented in randomized blocks except that the first trial of each session was always $0.3 \mathrm{M} \mathrm{NaCl}$ to encourage continued sampling. All salt solutions were made fresh using reagent grade chemicals (all salts from Fisher Scientific, Orlando, FL, except for NaGlu, which was from Sigma Chemical Co., St. Louis, MO) and distilled water. One liter of $100 \mu \mathrm{M}$ amiloride hydrochloride (Sigma Chemical Co.) stock solution was made the evening prior to testing and wrapped in aluminum foil and left on a stir pad overnight in a dark room. Two of the four gustometers contained the aforementioned salts dissolved in distilled water, whereas the remaining two gustometers contained salts dissolved in $100 \mu \mathrm{M}$ amiloride and $100 \mu \mathrm{M}$ amiloride in place of the distilled water stimulus. Half of the rats from each depletion group were tested with amiloride as the solvent.

At the time of testing, the remaining chow was removed from the home cage and weighed to determine how much was ingested in the previous 24 $\mathrm{hr}$ after attempting to account for spillage. Distilled-water intake and urine output for each rat were measured to the nearest $\mathrm{mL}$. A $2.0-\mathrm{mL}$ sample of 
urine was collected for each rat and frozen in labeled plastic centrifuge tubes for later analysis.

\section{Urine Analysis}

Urine was analyzed using a flame photometer (Model 480; Ciba Corning, East Walpole, MA 480) to determine sodium content for both sodiumdepleted and nondepleted rats. Urine from sodium-depleted rats was diluted with distilled water (4 parts water: 1 part urine) prior to analysis so that the sodium concentration of each sample would fall within the range testable by the device. The values for these animals were then multiplied by a factor of 5 .

\section{Data Analysis}

Lick data were recorded and analyzed for the entire $5 \mathrm{~s}$ of each trial, but the main parameter of interest was the number of licks to each stimulus during the last $3 \mathrm{~s}$ of each 5 -s trial. This was done to minimize the number of sampling licks included in the analysis. The local lick rate for rats is approximately $7 \mathrm{~Hz}$ (Corbit \& Luschei, 1969; Halpern, 1977), making 35 licks the ceiling in a 5-s trial and 21 licks the highest performance attainable in a 3-s period. The number of licks for each stimulus was then averaged for each group and compared using analyses of variance (ANOVAs) and $t$ tests (paired, independent, and one-sample tests). The statistical rejection criterion was set at .05 for all analyses. Significance values were adjusted using the Bonferroni method when a large number of $t$ tests were performed on the same data set. Lick data from an animal were included in the analyses only if the animal sampled all 11 stimuli in the test. Only 2 rats in the nondepleted-amiloride group and 1 rat in the nondepleted-water group passed this criterion. This sample size was too low for meaningful analysis, so all statistical tests of stimulus licking were performed on sodium-depleted rats only. Data from each rat were used, however, to analyze the number of trials initiated during testing and degree of sodium depletion for each of the four groups. Sodium balance was determined by subtracting urinary sodium output from sodium ingested.

\section{Results}

\section{Brief-Access Testing}

The overall pattern of responsiveness for the sodium-depleted groups was the same regardless of whether the 3-s avoidance period or the entire 5-s period was analyzed. One-way ANOVAs of mean licks during the last $3 \mathrm{~s}$ of each trial revealed a main effect of stimulus for both the amiloride, $F(10,90)=35.4, p<.001$, and distilled-water, $F(10,90)=2.7, p<.008$, solvent groups. Intake of distilled water and amiloride did not differ significantly between groups ( $p>.09,10.3 \pm 4$ vs. $13.6 \pm 4$ licks, respectively).

For rats in the distilled water condition, paired $t$ tests indicated that they licked significantly more to each of the six sodium stimuli (i.e., three salts, two concentrations) than to water ( $p<$ .005 for each $t$ test; Bonferroni adjusted $p<.05$; see Figure 1). Furthermore, a two-way ANOVA (Anion $\times$ Concentration) of responses to sodium salts revealed a significant main effect for concentration only, $F(1,9)=26.9, p<.002$. One-way ANOVAs indicated no differences in performance across sodium salts at the 0.03 -M concentration and a slight effect at the $0.3-\mathrm{M}$ concentration, $F(2,18)=3.99, p<.04$, with the greatest number of licks recorded for the salt with the intermediate-sized anion, sodium acetate $(\mathrm{NaAc})$. Paired $t$ tests indicated significantly less licking to the $\mathrm{NH}_{4} \mathrm{Cl}$ solutions than to water $(p<.008$ for both), but this significance disappeared with a Bonferroni test (adjusted $p \mathrm{~s}>$

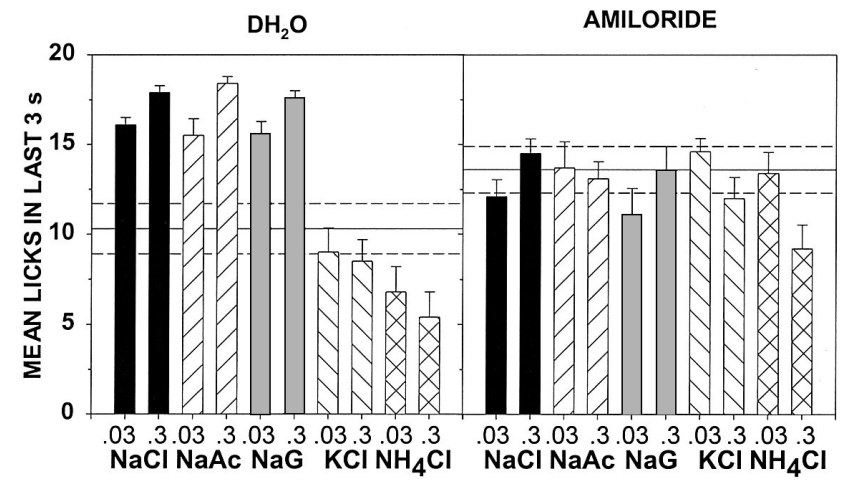

Figure 1. Brief-access licking to each stimulus by sodium-depleted rats. Mean $(+S E)$ number of licks taken by sodium-depleted rats in the last $3 \mathrm{~s}$ of each 5-s bout. Stimuli were dissolved in either distilled water (left) or $100 \mu \mathrm{M}$ amiloride (right). Horizontal lines indicate mean ( $\pm S E M$ ) number of licks to either distilled water $\left(\mathrm{DH}_{2} \mathrm{O}\right)$ or amiloride alone. All sodium salts (chloride $[\mathrm{NaCl}]$, acetate $[\mathrm{NaAc}]$, and gluconate $[\mathrm{NaG}]$ ) were preferred over water (paired $t$ tests, $p<.005$ for each; $p<.05$ Bonferroni adjusted), whereas none of the salts—-sodium or nonsodium (potassium chloride $[\mathrm{KCl}]$ and ammonium chloride $\left[\mathrm{NH}_{4} \mathrm{Cl}\right]$ ) — were preferred over amiloride. Responses to water and amiloride alone were not significantly different.

.07). The $\mathrm{KCl}$ stimuli were not different from water $(p>.34$ for both, unadjusted).

In the amiloride condition, .03 $\mathrm{M} \mathrm{NaGlu}$ and $.3 \mathrm{M} \mathrm{NH}_{4} \mathrm{Cl}$ were licked less than amiloride alone $(p<.05$ for both). Again, the statistical significance of this difference disappeared with a more conservative test (adjusted $p s>.4$ ). All other stimuli generated licking comparable to that induced by amiloride alone (all $p \mathrm{~s}>$ .14 , unadjusted). A two-way ANOVA (Anion $\times$ Concentration) for all sodium salts indicated that all six sodium stimuli were licked to similar degrees in the presence of amiloride $(p s>.14)$.

\section{Number of Trials Initiated}

It is not surprising that the animals in the sodium-depleted groups initiated a greater number of trials than rats in the nondepleted groups $(p<.001)$. However, sodium-depleted rats in the amiloride condition took far fewer trials than sodium-depleted rats in the distilled water condition ( $p<.001$; see Figure 2$)$. This suggests that although more motivated to lick than nondepleted rats, the presence of amiloride reduced the number of trials initiated by sodium-depleted rats.

\section{Sodium Balance}

All rats in the sodium-depleted groups were in negative sodium balance, whereas rats in the nondepleted groups ingested more sodium than they excreted ( $p<.004$ for each of the four groups). There was no difference in sodium balance between rats in the distilled water condition and those in the amiloride condition for either depletion group (both $p \mathrm{~s}>.20$ ).

\section{Discussion}

It is clear from the data that the sodium-specific appetite exhibited by rats in the distilled-water condition was not evident in the 


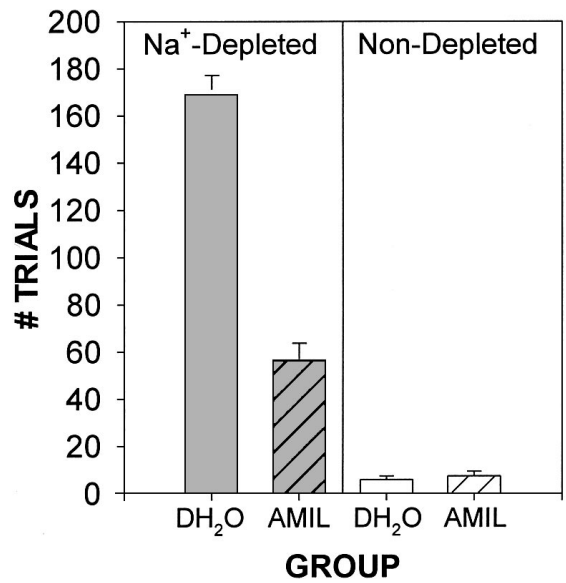

Figure 2. Mean $( \pm S E M)$ number of trials initiated by each group of rats. Nondepleted rats took the fewest trials regardless of whether amiloride (Amil) was present. Sodium (Na)-depleted rats, however, initiated considerably fewer trials in the presence of amiloride $(p<.001) . \mathrm{DH}_{2} \mathrm{O}=$ distilled water.

amiloride condition. When amiloride was added to the taste stimuli, intake of the sodium salts was not greater than intake of either the nonsodium salts $\mathrm{NH}_{4} \mathrm{Cl}$ and $\mathrm{KCl}$ or of $100 \mu \mathrm{M}$ amiloride alone, strongly suggesting that the animals were unable to recognize the sodium salts and to ingest them preferentially. These findings support previous reports of impaired sodium appetite with amiloride (Bernstein \& Hennessy, 1987; McCutcheon, 1991; Roitman \& Bernstein, 1999) and extend them by showing that the taste-guided specificity of the sodium appetite is completely abolished by amiloride treatment in a brief-access test. Moreover, sodium-depleted rats initiated significantly more trials than nondepleted rats regardless of whether amiloride was added to the stimuli. This indicates an increase in appetitive behavior (see Craig, 1918; Denton, 1982), even in the absence of a sodium taste cue. When the taste of sodium was present (i.e., amiloride was not used), sodium-depleted rats showed an even greater increase in the number of trials initiated. Thus, the taste of sodium in the absence of need does not produce an increase in appetitive behavior, whereas need in the absence of the sodium taste cue doesalthough not to the same degree as need and gustatory cue combined. In addition, rats in the amiloride condition licked more than rats in the distilled water condition when presented with a nonsodium salt. This may explain why in some cases sodium-depleted animals display modest increases in the intake of other solutions when sodium and lithium salts are not available (see Falk, 1965; Jalowiec, Crapanzano, \& Stricker, 1966). It remains to be tested whether the depletion-induced increase in trials initiated and nonspecific licking when stimuli were mixed with amiloride were due in part to the postingestive consequences of sodium intake as the session progressed. A sham-feeding preparation would be revealing in this regard.

This effect of amiloride on the specificity of the sodium appetite differentiates amiloride treatment from CT transection, which has been shown to impair but not always eradicate sodium-specific appetite (see Breslin et al., 1993; Markison et al., 1995). This difference is likely due to the fact that the greater superficial petrosal (GSP) branch of the facial nerve also contains amiloridesensitive fibers important for the maintenance of certain tasteguided tasks involving sodium (Roitman \& Bernstein, 1999; Sollars \& Hill, 1998). Our results also differ from those of CT transection in certain other regards. For instance, prior studies reported increased licking to low $\mathrm{KCl}$ concentrations with transection (Breslin et al., 1993) that we did not observe with amiloride treatment. This is most likely due to the fact that CT transection reduces the perceived intensity of $\mathrm{KCl}$ in rats whereas amiloride does not (Geran, Guagliardo, \& Spector, 1999), at least as assessed by detection threshold. Procedural differences between this experiment and the brief-access studies with CT transection should also be taken into account when comparing performance between experiments. These include a shorter sample time ( $5 \mathrm{~s}$ vs. $10 \mathrm{~s})$, a greater sodium:nonsodium salt ratio in the stimulus array (3:2 vs. $1: 4)$, and a slightly lower ( 0.03 vs. $0.05 \mathrm{M})$ concentration of $\mathrm{KCl}$ in the current experiment.

Also of critical importance is the fact that sodium-depleted rats in the distilled-water condition increased intake of all sodium salts ( $\mathrm{NaCl}$, sodium acetate, and sodium gluconate) to a similar degree. Although previous studies have reported that rats will lick a variety of sodium salts following sodium depletion (see Fregly, 1958; Handal, 1965; Nachman, 1962), the present study is the first sodium appetite experiment to our knowledge to include a variety of sodium salts and concentrations in a single brief-access test. Our results strongly suggest that eliminating, or at least severely reducing, the contribution of the AI transduction pathway by changing the size of the anion does not compromise sodium recognition. Thus, the AS sodium transduction pathway appears to be both necessary and sufficient for sodium recognition in the rat just as it is for normal sodium detection. Evidence of an apically located AI cation transduction pathway in the oral cavity of the rat (DeSimone et al., 2001; Gilbertson \& Zhang, 1998) may call this sufficiency into question if this nonselective apical pathway is substantially activated by large anion sodium salts like NaGlu. However, current electrophysiology indicates that only a negligible portion of the $\mathrm{CT}$ response to $\mathrm{NaAc}$ and $\mathrm{NaGlu}$ remains with amiloride treatment at the stimulus concentrations used (Elliot \& Simon, 1990; Formaker \& Hill, 1988; Ye et al., 1993). In addition, the GL responds poorly at best to $\mathrm{NaAc}$ and $\mathrm{NaGlu}$ at the concentrations used in this experiment (Formaker \& Hill, 1991; Kitada et al., 1998), a finding consistent with the lack of functional amiloridesensitive taste receptors in the posterior tongue (Doolin \& Gilbertson, 1993). Although sodium responses of the GSP can be inhibited by amiloride (Sollars \& Hill, 1998), it is not entirely clear how anion size might affect this suppression. Amiloride inhibited GSP responses to $\mathrm{NaCl}$ and $\mathrm{NaAc}$ roughly equivalently $(\sim 80 \%)$ at .1 and $.25 \mathrm{M}$, but at $.05 \mathrm{M}$, responses to $\mathrm{NaCl}$ were more suppressed $(\sim 75 \%)$ than responses to NaAc ( $\sim 50 \%$; Sollars \& Hill, 1998). Unfortunately, integrated responses to $\mathrm{NaAc}$ were not reported, making it difficult to assess whether this $25 \%$ difference was indeed substantial. Harada and colleagues (Harada, Yamamota, Yamaguchi, \& Kasahara, 1997) indicated that the integrated response to $0.1 \mathrm{M} \mathrm{NaAc}$ was considerably smaller than the response to $0.1 \mathrm{M} \mathrm{NaCl}$ but found a comparatively slight $30 \%$ inhibition with amiloride for $\mathrm{NaAc}$ and minimal inhibition for $\mathrm{NaCl}$. Differences in methodology are most likely the root of these discrepancies (see Sollars \& Hill, 1998). Although both studies suggest that the GSP is amiloride-sensitive, the effect of the anion on this 
sensitivity ranges from slight suppression (Harada et al., 1997) to no effect or even enhancement of sodium activation, depending on the concentration (Sollars \& Hill, 1998). If the GSP response to $\mathrm{NaAc}$ dissolved in amiloride is different from that of the CT, this might reflect differences between the characteristics of sodium channels located in the palate and those in the anterior tongue (Sollars \& Hill, 1998), or perhaps the presence of a transduction mechanism in the palate that is activated by acetate.

The functional role of the AI transduction pathway to taste function is yet to be understood but might involve the detection or recognition of nonsodium salts. Support for this hypothesis comes from a report that discrimination between $\mathrm{NH}_{4} \mathrm{Cl}$ and $\mathrm{KCl}$ is severely compromised with combined transection of the $\mathrm{CT}$ and GSP nerves but unaffected by amiloride treatment (Geran, Garcea, $\&$ Spector, 2002). This suggests that recognition and discrimination of these salts depends on amiloride-insensitive, saltresponsive units in these nerves. As noted previously, normal $\mathrm{KCl}$ detectability is also compromised by $\mathrm{CT}$ transection but not significantly affected by amiloride treatment, suggesting that AI units of the facial nerve are required for this task (Geran et al., 1999). Although the AI pathway does not appear to be necessary for rats to increase sodium intake when depleted of sodium, this route of transduction could be important for the satiation of other mineral appetites like that induced by calcium deprivation. Tordoff and colleagues have shown that rats deprived of calcium will exhibit increased acceptance of calcium chloride and other salts including $\mathrm{NaCl}$ and $\mathrm{NH}_{4} \mathrm{Cl}$ (Coldwell \& Tordoff, 1996; Tordoff, Ulrich, \& Schulkin, 1990). It is interesting to note that calcium-deprived rats did not show an increase in the amount of NaGlu consumed (Coldwell \& Tordoff, 1996). This could suggest that blocking the AI transduction pathway with gluconate disrupted the rat's ability to preferentially ingest sodium under these conditions. Discrimination among sodium salts might also depend on AI transduction. The CT response to $\mathrm{NaCl}$ is of greater magnitude than the response to $\mathrm{NaAc}$ or NaGlu because of a larger AI response (Elliot \& Simon, 1990; Formaker \& Hill, 1988; Ye et al., 1993). This comparative increase in $\mathrm{AI}$ response does not appear to confer any particular salience to $\mathrm{NaCl}$ over other sodium salts at nearthreshold levels in rats (Geran \& Spector, 2000b) but could affect the taste quality or intensity of sodium salts at superthreshold levels. Human subjects have rated $\mathrm{NaCl}$ as more intense than NaGlu at equimolar concentrations (Ossebaard \& Smith, 1995).

It is important to note that although there were no substantial differences in the number of licks across sodium salts in this experiment, this does not necessarily imply that these salts were perceived as isointense, isohedonic, or indiscriminable on the basis of taste quality. For example, Schulkin (1982) reported that sodium-deficient rats drank significantly more $.12 \mathrm{M} \mathrm{NaCl}$ than $.12 \mathrm{M} \mathrm{NaAc}$ in a 2-hr, two-bottle preference test, presumably because it was perceived as more intense. Our goal was to determine whether anion size, like amiloride, interferes with the rat's ability to perceive a sodium-like taste quality when postingestive factors are minimal. It is possible that an increase in the trial duration could produce significant differences in responsiveness across sodium stimuli.

Sodium-depleted rats in the distilled-water condition increased their intake of both 0.03 and $0.3 \mathrm{M} \mathrm{NaAc}$ and $\mathrm{NaGlu}$ relative to water, suggesting that the size of the anion did not affect their ability to perceive the taste of sodium. In the amiloride condition, however, rats did not lick $\mathrm{NaAc}$ or $\mathrm{NaGlu}$ more than amiloride alone at either stimulus concentration, suggesting that sodium recognition was compromised. This is particularly noteworthy at the $0.3 \mathrm{M} \mathrm{NaGlu}$ concentration because of the fact that rats were shown to detect this stimulus, albeit poorly, in the presence of amiloride (Geran \& Spector, 2000b). Together, these results suggest that rather than responding to sodium activation of the AS transduction pathway, the behavioral detectability of high NaGlu concentrations derives from some cue related to the gluconate anion or perhaps activation of the AI pathway due to leakage of sodium through tight junctions, or AI apical channels, as a result of the high $\mathrm{Na}^{+}$concentration gradient.

In summary, these data support Bernstein \& Hennessy's (1987) conclusion that the AS sodium transduction pathway is necessary for sodium recognition in the rat, and furthermore strongly suggest that this pathway is also sufficient (see Elliot \& Simon, 1990; Formaker \& Hill, 1988; Ye et al., 1993). We have also extended previous studies of the effects of amiloride on salt appetite to show that the sodium specificity of the appetite is completely abolished when the AS pathway is blocked, coupled with a modest increase in appetitive behavior. In addition, these findings suggest that although $\mathrm{NaGlu}$ concentrations higher than $0.1 \mathrm{M}$ are detectable in the presence of amiloride, they appear to lack the characteristic taste quality associated with sodium.

\section{References}

Bartoshuk, L. M., Murphy, C., \& Cleveland, C. T. (1978). Sweet taste of dilute $\mathrm{NaCl}$ : Psychophysical evidence for a sweet stimulus. Physiology \& Behavior, 21, 609-613.

Bernstein, I. L., \& Hennessy, C. J. (1987). Amiloride-sensitive sodium channels and expression of sodium appetite in rats. American Journal of Physiology: Regulatory, Integrative and Comparative Physiology, 253, R371-R374.

Brand, J. G., Teeter, J. H., \& Silver, W. L. (1985). Inhibition by amiloride of chorda tympani responses evoked by monovalent salts. Brain Research, 334, 207-214.

Breslin, P. A. S., Spector, A. C., \& Grill, H. J. (1993). Chorda tympani section decreases the cation specificity of depletion-induced sodium appetite in rats. American Journal of Physiology: Regulatory, Integrative and Comparative Physiology, 264, R319-R323.

Coldwell, S. E., \& Tordoff, M. G. (1996). Acceptance of minerals and other compounds by calcium-deprived rats: 24-h tests. American Journal of Physiology, 271, R1-R10.

Corbit, J. D., \& Luschei, E. S. (1969). Invariance of the rat's rate of drinking. Journal of Comparative and Physiological Psychology, 60, $119-125$.

Craig, W. C. (1918). Appetites and aversions as constituents of instincts. Biological Bulletin, 34, 91-107.

Denton, D. A. (1982). The hunger for salt. Berlin, Germany: SpringerVerlag.

DeSimone, J. A., \& Ferrell, F. (1985). Analysis of amiloride inhibition of chorda tympani taste response of rat to $\mathrm{NaCl}$. American Journal of Physiology: Regulatory, Integrative and Comparative Physiology, 249, R52-R61.

DeSimone, J. A., Lyall, V., Heck, G. L., Phan, T. T., Alam, R. I., Feldman, G. M., \& Buch, R. M. (2001). A novel pharmacological probe links the amiloride-insensitive $\mathrm{NaCl}, \mathrm{KCl}$ and $\mathrm{NH}_{4} \mathrm{Cl}$ chorda tympani responses. Journal of Neurophysiology, 86, 2638-2641.

Doolin, R., \& Gilbertson, T. A. (1993). Distribution and characterization of functional amiloride-sensitive sodium channels in rat tongue. Journal of General Physiology, 107, 545-554. 
Elliot, E. J., \& Simon, S. A. (1990). The anion in salt taste: A possible role for paracellular pathways. Brain Research, 535, 9-17.

Falk, J. L. (1965). Limitation to the specificity of $\mathrm{NaCl}$ appetite in sodiumdepleted rats. Journal of Comparative and Physiological Psychology, 60, 393-396.

Falk, J. L., \& Herman, T. S. (1961). Specific appetite for $\mathrm{NaCl}$ without postingestional repletion. Journal of Comparative and Physiological Psychology, 54, 405-408.

Formaker, B. K., \& Hill, D. L. (1988). An analysis of residual $\mathrm{NaCl}$ taste response after amiloride. American Journal of Physiology: Regulatory, Integrative and Comparative Physiology, 255, R1002-R1007.

Formaker, B. K., \& Hill, D. L. (1991). Lack of amiloride sensitivity in SHR and WKY glossopharyngeal taste responses to $\mathrm{NaCl}$. Physiology \& Behavior, 50, 765-769.

Fregly, M. J. (1958). Specificity of the sodium chloride appetite of adrenalectomized rats: Substitution of lithium chloride for sodium chloride. American Journal of Physiology, 195, 645-653.

Geran, L. C., Garcea, M., \& Spector, A. C. (2002). Transecting the gustatory branches of the facial nerve impairs $\mathrm{NH}_{4} \mathrm{Cl}$ vs. $\mathrm{KCl}$ discrimination in rats. American Journal of Physiology: Regulatory, Integrative and Comparative Physiology, 283, R739-R747.

Geran, L. C., Guagliardo, N. A., \& Spector, A. C. (1999). Chorda tympani nerve transection, but not amiloride, increases the $\mathrm{KCl}$ taste detection threshold in rats. Behavioral Neuroscience, 113, 185-195.

Geran, L. C., \& Spector, A. C. (2000a). Amiloride increases sodium chloride taste detection threshold in rats. Behavioral Neuroscience, 114, 623-634.

Geran, L. C., \& Spector, A. C. (2000b). Sodium taste detectability in rats is independent of anion size: The psychophysical characteristics of the transcellular taste transduction pathway. Behavioral Neuroscience, 114, $1229-1238$.

Gilbertson, T. A., \& Zhang, H. (1998). Characterization of sodium transport in gustatory epithelia from the hamster and rat. Chemical Senses, 23, 283-293.

Halpern, B. P. (1977). Functional anatomy of the tongue and mouth of mammals. In J. A. W. M. Weijnen \& J. Mendelson (Eds.), Drinking behavior (pp. 1-92). New York: Plenum Press.

Handal, P. J. (1965). Immediate acceptance of sodium salts by sodium deficient rats. Psychonomic Science, 3, 315-316.

Harada, S., Yamamoto, T., Yamaguchi, K., \& Kasahara, Y. (1997). Different characteristics of gustatory responses between the greater superficial petrosal and chorda tympani nerves in the rat. Chemical Senses, 22, 133-140.

Heck, G. L., Mierson, S., \& DeSimone, J. A. (1984, January 27). Salt taste transduction occurs through an amiloride-sensitive sodium transport pathway. Science, 223, 403-405.

Jalowiec, J. E., Crapanzano, J. E., \& Stricker, E. M. (1966). Specificity of salt appetite elicited by hypovolemia. Psychonomic Science, 6, 331-332.

Kitada, Y., Mitoh, Y., \& Hill, D. L. (1998). Salt taste responses of the IXth nerve in Sprague-Dawley rats: Lack of sensitivity to amiloride. Physiology \& Behavior, 63, 945-949.

Kloub, M. A., Heck, G. L., \& DeSimone, J. A. (1997). Chorda tympani responses under lingual voltage clamp: Implications for $\mathrm{NH}_{4}$ salt taste transduction. Journal of Neurophysiology, 77, 1393-1406.

Krieckhaus, E. E., \& Wolf, G. (1968). Acquisition of sodium by rats: Interaction of innate mechanisms and latent learning. Journal of Comparative and Physiological Psychology, 65, 197-201.

Markison, S., St. John, S. J., \& Spector, A. C. (1995). Glossopharyngeal nerve transection does not compromise the specificity of taste-guided sodium appetite in rats. American Journal of Physiology: Regulatory, Integrative and Comparative Physiology, 269, R215-R221.
McCutcheon, N. B. (1991). Sodium deficient rats are unmotivated by sodium chloride solutions mixed with the sodium channel blocker amiloride. Behavioral Neuroscience, 105, 764-766.

Morrison, G. R., \& Young, J. C. (1971). Taste control over sodium intake in sodium deficient rats. Physiology \& Behavior, 8, 29-32.

Nachman, M. (1962). Taste preferences for sodium salts by adrenalectomized rats. Journal of Comparative and Physiological Psychology, 55, $1124-1129$.

Ossebaard, C. A., \& Smith, D. V. (1995). Effect of amiloride on the taste of $\mathrm{NaCl}$, Na-gluconate and $\mathrm{KCl}$ in humans: Implications for $\mathrm{Na}^{+}$receptor mechanisms. Chemical Senses, 20, 37-46.

Rehnberg, B. G., Mackinnon, B. I., Hettinger, T. P., \& Frank, M. E. (1993). Anion modulation of taste responses in sodium-sensitive neurons of the hamster chorda tympani nerve. Journal of General Physiology, 101, 453-465.

Richter, C. P., \& Eckert, J. F. (1938). Mineral metabolism of adrenalectomized rats studied by the appetite method. Endocrinology, 22, 214 224.

Roitman, M. F., \& Bernstein, I. L. (1999). Amiloride-sensitive sodium signals and salt appetite: Multiple gustatory pathways. American Journal of Physiology: Regulatory, Integrative and Comparative Physiology, 276, R1732-R1738.

Schiffman, S. S., Lockhead, E., \& Maes, F. W. (1983). Amiloride reduces taste intensity of $\mathrm{Na}^{+}$and $\mathrm{Li}^{+}$sweeteners. Proceedings of the National Academy of Sciences, USA, 80, 6136-6140.

Schulkin, J. (1982). Behavior of sodium-deficient rats: The search for a salty taste. Journal of Comparative and Physiological Psychology, 96, $628-634$.

Schulkin, J. (1991). Sodium hunger: The search for a salty taste. Cambridge, England: Cambridge University Press.

Simon, S. A. (1992). Influence of tight junctions on the interaction of salts with lingual epithelia: Responses of chorda tympani and lingual nerves. Molecular Cellular Biochemistry, 114, 43-48.

Sollars, S. I., \& Hill, D. L. (1998). Taste responses in the greater superficial petrosal nerve: Substantial sodium salt and amiloride sensitivities demonstrated in two rat strains. Behavioral Neuroscience, 112, 991-1000.

Spector, A. C., Andrews-Labinski, J., \& Letterio, F. C. (1990). A new gustometer for psychophysical taste testing in the rat. Physiology \& Behavior, 47, 795-803.

Stewart, R. E., Heck, G. L., \& DeSimone, J. A. (1996). Taste-mixture suppression: Functional dissection of cellular and paracellular origins. Journal of Neurophysiology, 75, 2124-2128.

Tordoff, M. G., Ulrich, P. M., \& Schulkin, J. (1990). Calcium deprivation increases salt intake. American Journal of Physiology, 259, R411-R419.

Ye, Q., Heck, G. L., \& DeSimone, J. A. (1991, November 1). The anion paradox in sodium taste reception: Resolution by voltage clamp studies. Science, 254, 724-726.

Ye, Q., Heck, G. L., \& DeSimone, J. A. (1993). Voltage dependence of the rat chorda tympani response to $\mathrm{Na}^{+}$salts: Implications for the functional organization of taste receptor cells. Journal of Neurophysiology, 70, 167-178.

Ye, Q., Heck, G. L., \& DeSimone, J. A. (1994). Effects of voltage perturbation of the lingual receptive field on chorda tympani nerve responses to $\mathrm{Na}^{+}$and $\mathrm{K}^{+}$salts in the rat: Implications for gustatory transduction. Journal of General Physiology, 104, 885-907.

Received June 4, 2003

Revision received August 15, 2003

Accepted August 18, 2003 